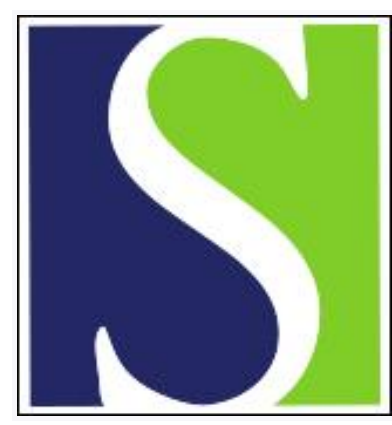

Scand J Work Environ Health 1993;19(1):63-65

https://doi.org/10.5271/sjweh.1502

Issue date: $01 \mathrm{Feb} 1993$

\title{
Solvents in pesticides.
}

by Petrelli G, Siepi G, Miligi L, Vineis P

Affiliation: Laboratorio di Epidemiologia e Biostatistica, Istituto Superiore di Sanita (National Institute of Health), Rome, Italy.

This article in PubMed: www.ncbi.nlm.nih.gov/pubmed/8465174

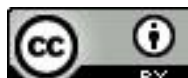




\title{
Solvents in pesticides
}

\author{
by Grazia Petrelli, ${ }^{1}$ Giuliano Siepi, ${ }^{1}$ Lucia Miligi, ${ }^{2}$ Paolo Vineis ${ }^{3}$
}

\begin{abstract}
PETRELlI G, SIEPI G, MILIGI L, VINEIS P. Solvents in pesticides. Scand J Work Environ Health 1993;19:63-5. Solvents are extensively used in pesticide formulations. This study concerns the solvents notified to the Italian Registry of Pesticides, which has information on approximately 8000 pesticide formulations. Solvents with evidence of carcinogenicity in humans or animals, including benzene, chloroform, carbon tetrachloride, 1,2-dichloroethane, 1,4-dioxane, and 2-nitropropane, have been notified for use in pesticides. Exposure to such solvents could partly explain some of the reported excesses of leukemia and non-Hodgkin's lymphoma among farmers.
\end{abstract}

Key terms: 1,2-dichloroethane, 1,4-dioxane, 2-nitropropane, benzene, chloroform, carbon tetrachloride, farmers, leukemia, non-Hodgkin's lymphoma.

Occupational handling and spraying of pesticides involves exposure to the active compound, but also to several different chemicals which are used as additives and solvents. Organic, and particularly chlorinated, solvents have been extensively used in the past in technical formulations. Since exposure levels are highest among mixers and loaders of pesticides, it is likely that these jobs are also associated with high levels of exposure to solvents (1). The presence of organic solvents in pesticides is highly relevant to cancer risk. Benzene and other solvents have been causally linked with leukemia (2). Leukemia and non-Hodgkin's lymphoma have also been found to have a high incidence among farmers (3) and subjects occupationally exposed to some pesticides ( 3 , 4). However, none of the studies reporting risks associated with pesticide exposure have given information on the solvents used.

In this presentation we report information on the solvents notified to the National Registry of Pesticides at the Italian National Institute of Health.

\section{Materials and methods}

The National Registry of Pesticides has been operating at the Italian National Institute of Health since 1984. According to Italian law, the marketing of a pesticide must be authorized by the Ministry of

Laboratorio di Epidemiologia e Biostatistica, Istituto Superiore di Sanità (National Institute of Health), Rome, Italy.

2 Centro per lo Studio e la Prevenzione Oncologica, via S Salvi, Firenze, Italy.

3 Unit of Cancer Epidemiology, Dipartimento di Scienze Biomediche e Oncologia Umana, Torino, Italy.

Reprint requests to: Dr G Petrelli, Laboratorio di Epidemiologia e Biostatistica, Istituto Superiore di Sanità, viale Regina Elena 299, Roma, Italy.
Health. The Registry receives information on all of the technical formulations of pesticides and their single active ingredients or additives which are notified to the Ministry of Health. The information registered is the tradename, the active ingredient(s), the solvents used, and the name of the producer (5). The Registry has information on about 8000 technical formulations proposed for use in Italy between 1970 and 1990. The fact that a specific pesticide (and its ingredients) has been notified to the Registry does not imply that it has been actually used in Italy.

\section{Results}

We analyzed the information concerning solvents notified to the Registry for use in pesticide formulations. Overall, we identified 71 different solvents (table 1). Many of them were known to be actually present in technical formulations (eg, xylene in 924), while others were only notified for use with no knowledge of actual use. The solvents were then classified according to the degree of evidence of carcinogenicity, as assessed within the monograph program of the International Agency for Research on Cancer (IARC) $(2,6)$. Table 1 presents the degree

Table 1. Solvents notified to the Registry of Pesticides of the Italian National Institute of Health for use in pesticide formulations according to the number of technical formulations in which they were known to be present and evidence of carcinogenicity according to the IARC monograph program (6).

\begin{tabular}{lcccc}
\hline Chemical name & $\begin{array}{c}\text { Technical } \\
\text { formulations } \\
(\mathrm{N})\end{array}$ & \multicolumn{2}{c}{$\begin{array}{c}\text { Evidence of } \\
\text { carcinogenicity }\end{array}$} \\
\cline { 3 - 5 } & 4 & & Humans & Animals \\
\hline Aniline & 5 & & $\mathrm{NE}$ & $\mathrm{NE}$ \\
Aromatic hydrocarbon & 1 & & $\mathrm{NE}$ & $\mathrm{NE}$ \\
2-Bentanol & 3 & & $\mathrm{~S}$ & $\mathrm{~S}$ \\
Benzene & 66 & & $\mathrm{NE}$ & $\mathrm{NE}$ \\
Butyl alcohol & & & \multicolumn{3}{c}{ (continued) }
\end{tabular}


Table 1. Continued.

\begin{tabular}{|c|c|c|c|}
\hline \multirow[t]{2}{*}{ Chemical name } & \multirow{2}{*}{$\begin{array}{l}\text { Technical } \\
\text { formulations } \\
(\mathrm{N})\end{array}$} & \multicolumn{2}{|c|}{$\begin{array}{l}\text { Evidence of } \\
\text { carcinogenicity }\end{array}$} \\
\hline & & Humans & Animals \\
\hline Butylglycol & - & NE & NE \\
\hline Carbon tetrachloride $^{b}$ & 16 & 1 & $S$ \\
\hline Chloroform & 2 & $i$ & $\mathrm{~S}$ \\
\hline Chloropenthane & 1 & NE & NE \\
\hline Cresol & - & NE & NE \\
\hline Cyclohexanol & - & NE & NE \\
\hline Cyclohexanone & 186 & ND & I \\
\hline Dibromomethane & - & NE & NE \\
\hline 1,2-Dichlorobenzene & - & i & 1 \\
\hline 1,1-Dichloroethane & - & NE & NE \\
\hline 1,2-Dichloroethane & 2 & ND & $\mathrm{S}$ \\
\hline Dichloroethylene & 二 & NE & NE \\
\hline 1,1-Dichloroethylene & - & NE & NE \\
\hline 1,2-Dichloropropane & - & ND & L \\
\hline Diethylbenzene & 1 & NE & NE \\
\hline Dimethyl carbonate & - & NE & NE \\
\hline $\mathrm{N}, \mathrm{N}$-Dimethylformamide & 17 & L & 1 \\
\hline 1,4-Dioxane & 2 & $\overline{\mathrm{I}}$ & $\mathrm{S}$ \\
\hline Ethanol & 2 & NE & NE \\
\hline Ethylbenzene & - & NE & NE \\
\hline Ethylene glycol & 221 & NE & NE \\
\hline Ethylglycol & 24 & NE & $\mathrm{NE}$ \\
\hline Formol & 1 & $\mathrm{NE}$ & NE \\
\hline Furfuryl alcohol & 4 & NE & NE \\
\hline Isophorone & 32 & NE & $\mathrm{NE}$ \\
\hline Isopropylglycol & - & NE & NE \\
\hline Kerosene & 2 & NE & NE \\
\hline Mesithyl oxide & 3 & NE & NE \\
\hline Mesithylene & 8 & NE & NE \\
\hline Methanol & 17 & NE & NE \\
\hline 2-Methoxypropanol & - & NE & NE \\
\hline Methylmetacrylate & - & ND & 1 \\
\hline Methylcyclohexanol & - & NE & NE \\
\hline Methylcyclohexanone & - & $\mathrm{NE}$ & NE \\
\hline Methylglycol & 10 & NE & NE \\
\hline Methylisobuthylcarbinole & - & $\mathrm{NE}$ & NE \\
\hline N-Methylpyralidone & - & NE & NE \\
\hline Monochlorobenzene & 17 & NE & NE \\
\hline Naphtha & 41 & $\mathrm{NE}$ & NE \\
\hline Nitrile acetic acid & 4 & NE & NE \\
\hline Nitrobenzene & - & NE & NE \\
\hline 1-Nitropropane & 1 & NE & NE \\
\hline 2-Nitropropane & 1 & ND & $\mathrm{S}$ \\
\hline Oil of turpentine & - & NE & NE \\
\hline 0-Chlorotoluene & 1 & NE & NE \\
\hline Paraffin & - & NE & NE \\
\hline Pentachloroethane & - & ND & $\mathrm{L}$ \\
\hline Phenol & 1 & NE & NE \\
\hline Propylbenzene & - & NE & NE \\
\hline Propylbromide & - & NE & NE \\
\hline Propyl chloride & - & NE & NE \\
\hline Propylene glycol & 59 & NE & NE \\
\hline Pyridine & - & NE & $\mathrm{NE}$ \\
\hline Styrene & - & I & $\mathrm{L}$ \\
\hline Tetrabenzylphenol & - & NE & NE \\
\hline $1,1,2,2$-Tetrachloroethane & - & i & $\mathrm{L}$ \\
\hline Tetrachloroethylene & 4 & I & $\mathrm{L}$ \\
\hline Tetrahydrofuran & - & NE & NE \\
\hline Tetrahydronaphthalene & 1 & NE & NE \\
\hline Toluene & 4 & 1 & 1 \\
\hline $1,1,1$-Trichloroethane & 14 & ND & I \\
\hline 1,1,2-Trichloroethane & 1 & ND & L \\
\hline Trichloroethylene & 1 & 1 & $\mathrm{~L}$ \\
\hline Trimethylbenzene & 9 & NE & $\mathrm{N} E$ \\
\hline Vinyltoluene & - & $\mathrm{NE}$ & $\mathrm{NE}$ \\
\hline Xylene & 924 & 1 & 1 \\
\hline
\end{tabular}

a $\mathrm{I}=$ inadequate evidence, $\mathrm{L}=$ limited evidence, $N D=\mathrm{no}$ data available, $\mathrm{NE}=$ data not evaluated, $\mathrm{S}=$ sufficient evidence.

b Used as an active ingredient.
Table 2. Active ingredients of the technical formulations containing solvents with sufficient evidence of carcinogenity in humans or animals.

\begin{tabular}{|c|c|}
\hline Solvent & $\begin{array}{l}\text { Active ingredient of the } \\
\text { pesticide formulation }\end{array}$ \\
\hline Benzene & Cypermethrin (10\%) \\
\hline Benzene + xylene & Alachlor $(30 \%)$ \\
\hline $\begin{array}{l}\text { Benzene + xylene + } \\
\text { cyclohexanol }\end{array}$ & Dimethoate $(38 \%)$ \\
\hline Carbon tetrachloride & Used as active ingredient \\
\hline Chloroform & Dichlorvos (25\%) \\
\hline 1,2-Dichloroethane & $\begin{array}{l}\text { Glycerophthalic resin (50\%) } \\
\text { Polyglycerylphthalate }(-)\end{array}$ \\
\hline 1,4-Dioxane + 2-nitropropane & Metaldehyde (5\%) \\
\hline 1,4-Dioxane + cyclohexanol & Binapacryl $(80 \%)$ \\
\hline
\end{tabular}

of evidence of carcinogenicity in humans and experimental animals for each solvent which has been considered in IARC monographs 1 through 53. For each solvent, the table also reports the number of technical formulations in which it was known to be present.

For solvents with sufficient evidence of carcinogenicity, either in humans or in animals, table 2 presents the names of the active ingredients of the technical formulations in which they were used.

\section{Discussion}

Through an examination of about 8000 pesticide formulations registered in the Registry of Pesticides at the Italian National Institute of Health, we have identified 71 different solvents notified for use. Some of these solvents have "sufficient" evidence of carcinogenicity in humans or animals or both, including benzene and other chlorinated compounds. The presence of such chemicals in pesticides indicates that the exposure of farmers and appliers could occur; exposure would be particularly high in the case of mixers and loaders.

Several studies among farmers have found excess risks for leukemia and non-Hodgkin's lymphoma (3). One study in particular has reported elevated relative risks for leukemia among subjects exposed to crotoxyphos, dichlorvos, famphur, pyrethrins, and metoxychlor (4). According to our survey, dichlorvos, extensively used in Italy in the past, contains chloroform (a carcinogen in animals), xylene, 1,1,1trichloroethane, butyl alcohol, and aliphatic hydrocarbons. Although there is clear evidence of carcinogenicity for only one of these chemicals, the presence of chlorinated solvents in many pesticides might at least partly explain some of the leukemia excesses.

Future epidemiologic studies on the risk of cancer among farmers should consider solvents as one of the relevant exposures. This goal could be attained, for example, by the use of pesticide-solvent matrices in case-referent studies. 


\section{Acknowledgments}

Part of this work was made possible by a grant from the United States National Cancer Institute to Paolo Vineis (grant no 1-R01 CA51086-01A2). The contents of the publication are solely the responsibility of the authors and do not necessarily represent the official view of the National Cancer Institute.

\section{References}

1. International Agency for Research on Cancer (IARC). Occupational exposures in insecticide application, and some pesticides. Lyon: IARC, 1991. (IARC monographs on the evaluation of carcinogenic risks to humans; vol 53.)

2. International Agency for Research on Cancer (IARC). Overall evaluations of carcinogenicity: an updating of
IARC monographs, volumes 1 to 42 . Lyon: IARC, 1987. (IARC monographs on the evaluation of carcinogenic risks to humans; suppl 7.)

3. Blair A, Hoar Zahm S. Cancer among farmers. In: Philadelphia, PA: Hanley and Belfus Inc, 1991. (Occupational medicine: state of the art reviews; vol 6, no 3)

4. Morris Brown L, Blair A, Gibson R, Everett GD, Cantor KP, Schuman LM, et al. Pesticide exposures and other agricultural risk factors for leukemia among men in Iowa and Minnesota. Cancer Res 1990;50:6585-91.

5. Giuli B, Petrelli G, Siepi G, Verdecchia A. I formulati antiparassitari in Italia negli anni 1971-85. Rome: Istituto Superiore di Sanità, 1991.

6. International Agency for Research on Cancer (IARC). IARC monographs on the evaluation of carcinogenic risks to humans. Volumes 1 to 53. Lyon: IARC, 19721991.

Received for publication: 3 August 1992 